\title{
Effects of various solvents on the liquefaction of biomass to produce fuels and chemical feedstocks
}

\author{
Zhengang Liu ${ }^{\mathrm{a}, \mathrm{b}}$, Fu-Shen Zhang ${ }^{\mathrm{a}, *}$ \\ ${ }^{a}$ Research Center for Eco-Environmental Sciences, Chinese Academy of Sciences, 18 Shuangqing Road, Beijing 100085, China \\ ${ }^{\mathrm{b}}$ Graduate University of Chinese Academy of Sciences, Beijing 100039, China
}

\section{A R T I C L E I N F O}

\section{Article history:}

Received 29 December 2007

Accepted 5 August 2008

Available online 19 September 2008

\section{Keywords:}

Biomass liquefaction

Solvent

Hydrothermal treatment

Solvolysis

\begin{abstract}
A B S T R A C T
The liquefaction of pinewood in the presence of various solvents (water, acetone and ethanol) was studied so as to investigate the solvent effects on the biomass liquefaction process. Experiments were conducted in an autoclave in the conditions of temperature range $523-723 \mathrm{~K}$, starting pressure $1 \mathrm{MPa}$, reaction time $20 \mathrm{~min}$, biomass $10 \mathrm{~g}$ and solvent $60 \mathrm{~g}$, respectively. The liquid products and solid residues were characterized by GC-MS and FTIR. The results showed that the liquefaction products were greatly affected by the solvent type. With acetone as extraction agent, 4-methyl-1,2-benzenediol was one of the major compounds, while ethanol favored the formation of (E)-2-methoxy-4-(1-propenyl)-phenol and water significantly narrowed the products distribution. Among the tested solvents, acetone had the highest conversion rate, while the highest oil yield reached $26.5 \%$ at $473 \mathrm{~K}$ in ethanol. The FTIR analysis showed that cellulose liquefaction speed in water preceded in acetone and ethanol, and the solid residue consisted of solid carbon and a little amount of lignin fragments at $723 \mathrm{~K}$.
\end{abstract}

(c) 2008 Elsevier Ltd. All rights reserved.

\section{Introduction}

Renewable energy is growing important in responding to concerns over the environment pollution and the shortage of energy supplies $[1,2]$. Biomass is viewed as one of the most important potential and the only carbon-containing renewable energy resources. The term biomass can generally be defined as all the biologically produced matter, mainly in form of abundant agricultural and forestry wastes [3]. In the past decades, biochemical (such as methane and alcoholic fermentation) and thermal-chemical conversion technologies and processes have been studied for the utilization of biomass as feedstock for chemicals and bio-fuels [4-7]. In these methods, thermal liquefaction is considered to be most promising method obtaining low molecular weight liquid, gas fuel and solid residue. Among thermal liquefaction conversion, pyrolysis and solvolysis are two main research focuses on converting biomass to more useful chemicals and fuels. Thus far, nearly 100 different biomasses, such as nutshell, corn stover, cherry stones, pinewood, sawdust, have been employed pyrolysis conditions, [8]. However, the high operating temperature of pyrolysis (673-1273 K) can lead to cross-linking reaction between hydrocarbons and aromatics resulting in tar which is difficult to further decompose. The solvolysis has many advantages such as (1) The presence of solvent dilute the concentration of the products pre-

\footnotetext{
* Corresponding author. Tel./fax: +86 1062849515.

E-mail address: fszhang@rcees.ac.cn (F.-S. Zhang).
}

venting the cross linked reactions and reverse reactions and (2) Relative low temperature (less energy consumption) in comparison with pyrolysis and gasification. Solvent has remarkable effect on the liquefaction reaction, for example, the use of supercritical alcohol, rather than water successes in converting low rank coal into liquid oil $[9,10]$. Some articles have been reported about the solvolysis liquefaction of biomass and the presences of organic solvents are proven effectively to lower the viscosity of heavy oil derived from biomass liquefaction [11]. Because of the economic and environmental reasons, tested solvents of industrial interests tended to be those derivable from the biomass itself (e.g., alcohol, ketone) or to water $[12,13]$. Karagoz et al. carried out low temperature $(<553 \mathrm{~K})$ liquefaction in water and investigated the effects of treatment conditions including catalyst, temperature and reaction time [14-16]. The thermal liquefaction of white birch wood and filter pulp was studied in water and methanol vapor at 2 MPa pressure in a flow-through reactor [17]. Demirbas reported wood and agricultural materials were delignified in either glycerol or alkaline glycerol in aqueous or non-aqueous media for the production of pulps [18]. Cemek et al. investigated the verbascum stalk liquefaction by supercritical fluid extraction and the resulting liquid product was divided into benzene and ethyl ether soluble fraction [19]. High conversions were realized on depolymerization of Kraft- and organosolv-derived lignin by $\mathrm{KOH}$ in supercritical methanol or ethanol was studied in rapidly heated batch microreactor and model compound studies confirmed that the dominant depolymerization route is the solvolysis of ether linkages [20]. Biomass liquefaction 
product is determined by various factors, including substrate type, heating conditions, solvent type, reactor configuration and catalyst.

To the best of our knowledge, solvolysis liquefaction of biomass has been carried out with some solvents, but the investigations cannot be compared due to the difference in the separation of products and definition of the liquid product and there is no studies carried out at identical conditions to understand the effect of solvent on the conversion rate, oil yield and product distribution. In the present paper we reported systemically the determination of solvent (water, ethanol and acetone) effect on the biomass liquefaction process. Especially for ethanol, biomass-to-ethanol fermentation produces a large quantity of lignin by-product, thus investigation of the ethanol on the biomass conversion (except fermentable fraction) is practicable to enhance the economic competitiveness of biomass-to-ethanol conversion. This work is part of our ongoing attempt to make a process to generate desired product more selective and controllable in the biomass liquefaction process.

\section{Experimental}

\subsection{Materials}

Biomass (pinewood) was obtained from a wood processing factory in Beijing suburb. The samples were firstly dried at $378 \mathrm{~K}$ for $24 \mathrm{~h}$ and then ground to less than 80 meshes. The chemical and elemental analysis of the pinewood sample was shown in Table 1. Ethanol, acetone and sodium sulfate were purchased from Beijing Chemicals Company (analytical grade) and used as received. The impurities in ethanol and acetone were identified through blank tests before experiments.

\subsection{Solvolysis liquefaction process}

The experiments were conducted in a $200 \mathrm{ml}$ cylindrical autoclave made of 316 stainless steel and the autoclave can be operated at a maximum temperature of $873 \mathrm{~K}$ and maximum pressure of $65 \mathrm{MPa}$. In each test, the reactor was charged with $10 \mathrm{~g}$ pinewood and $60 \mathrm{~g}$ solvent and sealed. The air inside the autoclave was purged by argon gas for three times, then pressure in the autoclave was raised to $1 \mathrm{MPa}$ with argon gas to avoid solvent vaporization. The reactor was heated to required temperature at $10-13 \mathrm{~K} / \mathrm{min}$ where it was maintained for 20 min with less than $\pm 5 \mathrm{~K}$ variation. After the treatment, an electric fan was used to quickly cool the reactor to room temperature.

The procedure for separation and extraction of reaction product was given in Fig. 1. Briefly, the gas was removed from the autoclave after the reactor was cooled to room temperature and then the autoclave was opened. The solid and liquid mixture was removed from the autoclave and acidified by concentrated $\mathrm{HCl}$ to $\mathrm{pH} \sim 2-3$ (for ethanol and acetone liquefaction tests, the solvent was firstly removed from the solid and liquid mixture in rotary evaporator and then $50 \mathrm{ml}$ de-ionized water was added to the mixture before acidification). The solid and liquid in the mixture were separated by vacuum filtration. The liquid fraction was extracted with ethyl ether and the solid fraction was ultrasonically extracted with acetone. Ethyl ether and acetone extractants were removed in a rotary

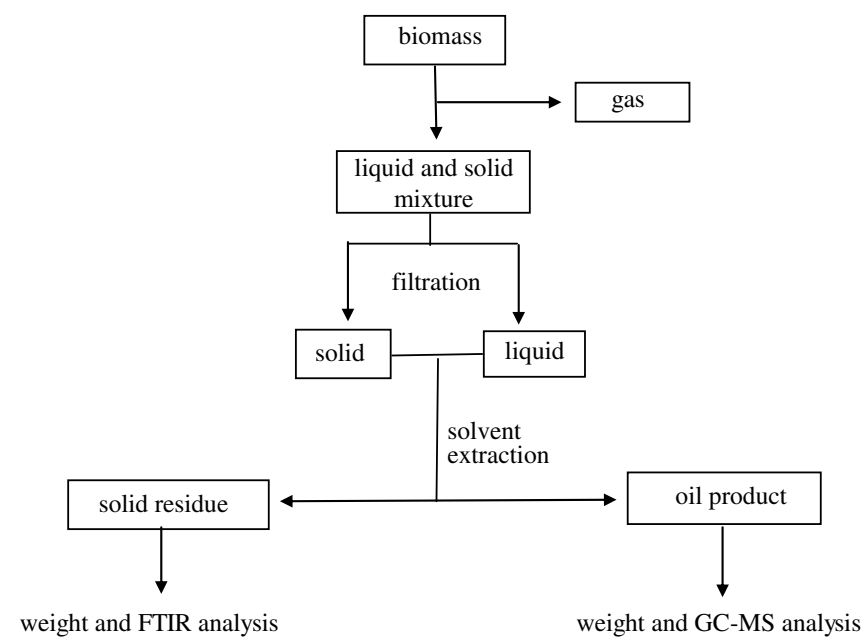

Fig. 1. A brief scheme of the product separation and analysis approach.

evaporator and the corresponding fraction was weighted and designated as oil A and oil B, respectively. Solid residue was defined as acetone insoluble fraction. Water in the oil was removed by anhydrous sodium sulfate. The conversion rate and oil yield were calculated by the following two formulas:

Conversion rate $=[1-($ weight of solid residue $)] /$ (weight of the feedstock)

Oil yield $=($ oil $\mathrm{A}+$ oil $\mathrm{B}) /($ weight of the feedstock $)$

\subsection{Analysis methods}

Biomass derived oil (oil A and oil B) was analyzed by a gas chromatograph equipped with mass selective detector (GC-MS, Agilent 7890A/5975C, USA). Both injector and detector were kept at $553 \mathrm{~K}$ and the carrier gas He velocity was $1 \mathrm{ml} / \mathrm{min}$. HP-5 column (5\% phenyl methyl siloxane, $30 \mathrm{~m} \times 250 \mu \mathrm{m} \times 0.25 \mu \mathrm{m}$ ) was used. In order to give good product separation, the oven program was $1 \mathrm{~min}$ isothermal at $313 \mathrm{~K}$, followed by a heating rate of $6 \mathrm{~K} / \mathrm{min}$ to final $553 \mathrm{~K}$ and hold $5 \mathrm{~min}$ at the final temperature. The injected volume was $1 \mu \mathrm{l}$ with split ratio of $30 / 1$. The elemental analysis was carried out using a flash EA1112 Elemental Analyzer. The solid residue was dried at $378 \mathrm{~K}$ for $24 \mathrm{~h}$ and analyzed using $\mathrm{KBr}$ pelletization method on a Nicolet Nexus 670 (USA).

\section{Results and discussion}

\subsection{Effect of solvent type on conversion rate}

Liquefaction of pinewood with three different solvents (water, acetone and ethanol) was studied under identical experiment conditions. Average conversion rates from three replicate tests were shown in Fig. 2. Among the three tested solvents, acetone had the best effect on the conversion in all the tested temperatures and the highest conversion rates were $74.2 \%, 69.4 \%$ and $75.9 \%$ with

Table 1

Elemental and chemical composition of the pinewood

\begin{tabular}{|c|c|c|c|c|c|c|c|c|c|}
\hline \multicolumn{5}{|c|}{ Elemental analysis (wt.\%) } & \multicolumn{4}{|c|}{ Chemical composition (wt.\%) } & \multirow{2}{*}{$\begin{array}{l}\text { LHV } \\
(\mathrm{MJ} / \mathrm{kg})\end{array}$} \\
\hline $\mathrm{C}$ & $\mathrm{H}$ & 0 & $\mathrm{~N}$ & $\mathrm{~S}$ & Cellulose & Hemicellulose & Lignin & Ash & \\
\hline 49.25 & 6.18 & $44.17^{\mathrm{a}}$ & 0.30 & 0.10 & 37 & 38 & 22 & 0.30 & 16.32 \\
\hline
\end{tabular}

a By difference. 


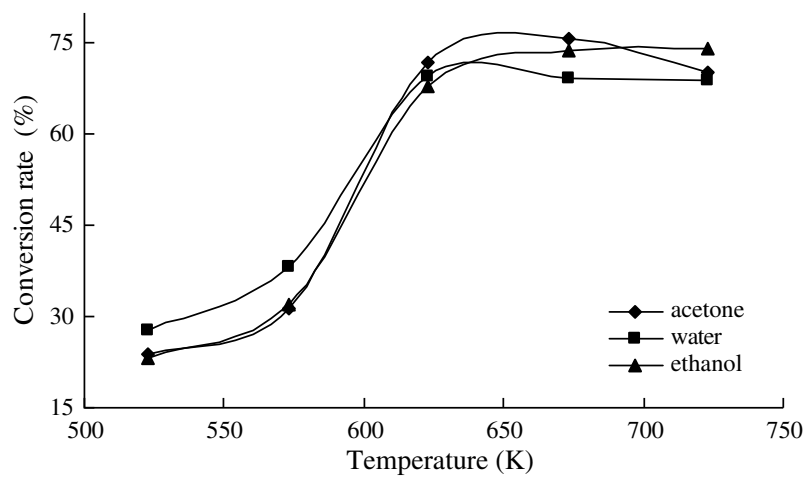

Fig. 2. Effect of solvent type on pinewood conversion rate as a function of temperatures. Other conditions: reaction time $20 \mathrm{~min}$, starting pressure $1 \mathrm{MPa}$.

ethanol, water and acetone as solvent, respectively. On the other hand, it was noted when the temperature was relative low $(<623 \mathrm{~K})$, water had the highest conversion rate. In a study on the cellulose liquefaction Jakab et al. reported that the temperature range of cellulose decomposition became wider and shifted to lower temperature with increasing water content of the solvent vapor [17]. Accordingly, the trend stemmed from quick decomposition of the cellulose and this explanation was confirmed by the FTIR analysis of the solid residue below (Fig. 4). The different conversion rate in liquefaction process may due to the polarity constant values of the solvent [21]. In biomass liquefaction process, ionic reactions as well as free radical reactions took place in the closed system including nucleophilic, electrophilic, elimination reaction $[22,23]$. It was known that most of these reactions are related to the polarity of the reaction system. Higher conversion rate was obtained in solvent with higher polarity. The dipole moment of water, ethanol and acetone at their critical point are about 1.8, 1.7 and $2.9 \mathrm{D}$, respectively. In addition, acetone can also act as a reaction substrate reacting with pinewood decomposition intermediates and the reactions of solid residue formation from decomposition intermediates were prevented resulting in high conversion rate.

\subsection{Effect of solvent type on oil yield}

Table 2 summarized the results of oil yield with water, ethanol and acetone as liquefaction solvents at various temperatures. The highest yields reached $18.6 \%, 26.5 \%$ and $20.0 \%$ at $573 \mathrm{~K}, 673 \mathrm{~K}$ and $673 \mathrm{~K}$ for the three tested solvents, respectively. It was observed that oil yield increased with increasing temperature up to a certain value ( $573 \mathrm{~K}$ for water and $673 \mathrm{~K}$ for ethanol and acetone) and decreased thereafter for all the tested solvents. This could be attributed to the result of the following competitive reactions: (1) formation of solid by cyclization, condensation and re-polymerization of the liquid products and formation of gases from degradation of the liquid products and (2) formation of liquid products by decomposition of the solid and aggregation of the gases. It could be concluded that the effect of enhanced temperature on the reaction (2) outweighed reaction (1) from the observation. In the present study, ethanol had the highest oil yield and the highest yield was
$11.4 \%$ and $18.2 \%$ for oil A and oil B obtained at $673 \mathrm{~K}$ and $623 \mathrm{~K}$ respectively. Consequently, considering the oil yield, the solvent efficiency in the biomass liquefaction can be sequenced as follows: ethanol $>$ acetone $>$ water.

\subsection{Effect of solvent type on product distribution}

Table 3 (oil A) and Table 4 (oil B) presented the identified compounds in the oils obtained from biomass liquefaction in the three solvents under a starting pressure of $1 \mathrm{MPa}$ and at $623 \mathrm{~K}$ for $20 \mathrm{~min}$ (only compounds with more than $1 \%$ of total area were shown). The area\% for each compound identified (defined by the percentage of the compound's chromatographic area out of the total area) and the total area\% for all the listed compounds were also shown in the Tables. It can be seen that the product categories and abundance were greatly affected by the solvent type.

According to GC-MS analysis results, the main difference between oil A and oil B was boiling points of the constituted compounds. The compounds in oil A have lower boiling points with retention time less than $25 \mathrm{~min}$. In oil A of the three tested solvents liquefaction, 2-methoxy-phenol, 2-methoxy-4-methyl-phenol, 1,2benzenediol and 1-(4-hydroxy-4-methoxyphenyl)-ethanone could all be detected, while they had significantly different relative abundance (e.g., 1,2-benzenediol, $10.00 \%, 3.57 \%$ and $4.05 \%$ of total area for water, ethanol and acetone, respectively). The major compound was 2-methoxy-phenol (17.20\%) for water liquefaction, while 2methoxy-4-methyl-phenol (8.23\%) for ethanol liquefaction and 4methyl-1,2-benzenediol (9.49\%) for acetone liquefaction. It can be seen that water liquefaction process favored the production of 2-methoxy-phenol and 1,2-benzenediol (17.20\% and $10.00 \%$ respectively) while more substituted phenol and 1,2-benzenediol compounds were produced in acetone and ethanol solvent liquefaction. These results were in good agreement with our previous suggestion that acetone and ethanol could act as substrates which further reacted with pinewood decomposition fragment and as a consequence more substituted compounds formed.

As for oil B, it was viscous dark liquid at room temperature. Fig. 3 showed that, there was notable difference in term of peaks intension and major peaks between the spectra of acetone extracts from the three solvents. The ethanol liquefaction product showed more major peaks than water and acetone, that is, comparatively wider product distribution. For water liquefaction products, three major peaks appeared at about $11.44,34.67$ and 36.35 min identified as 2-methoxy-phenol,benzene-acetic acid, 4-hydroxy-3-methoxy-methyl ester and 1-PA acid [1-phenanthrenecarboxylic acid, 1,2,3,4,4a,9,10,10a-octahydro-1,4a-dimethyl-7-(1-methyl)-methyl ester, $(1 R, 4 \mathrm{a} S, 10 \mathrm{a} R)-]$ respectively and these three compounds accounted for about $34.41 \%$ of total peak area. The major compound for ethanol liquefaction was (E)-2-methoxy-4-(1- propenyl)-phenol $(11.85 \%)$ with retention time $19.80 \mathrm{~min}$. Acetone liquefaction products had medium peaks. The compound 3-methylene-2pentanone was detected at $4.48 \mathrm{~min}(5.48 \%)$ and was not found at ethanol and water liquefaction process. Only five compounds with more than $1 \%$ area, namely 4-hydroxy-4-methyl-2-pentanone, 2-methoxy-phenol, 2-methoxy-4-methyl-phenol, 4-ethyl-2methoxy-phenol and 1-PA acid were all present in the three tested solvents liquefaction process.

Table 2

Oil yields from pinewood liquefaction in the tested solvents at different temperatures

\begin{tabular}{|c|c|c|c|c|c|c|c|c|c|c|c|}
\hline \multirow{2}{*}{$\frac{\text { Solvent }}{\text { Oil (wt.\%) }}$} & \multicolumn{2}{|c|}{$523 \mathrm{~K}$} & \multicolumn{2}{|c|}{$573 \mathrm{~K}$} & \multicolumn{2}{|c|}{$623 \mathrm{~K}$} & \multicolumn{2}{|c|}{$673 \mathrm{~K}$} & \multicolumn{2}{|c|}{$723 \mathrm{~K}$} & \multirow[t]{2}{*}{ The highest yield (oil $A+$ oil $B$ ) } \\
\hline & A & B & A & B & A & B & A & B & A & B & \\
\hline Acetone & 2.1 & 5.5 & 2.2 & 8.1 & 4.1 & 11.9 & 5.6 & 14.4 & 8.1 & 11.2 & 20.0 \\
\hline Water & 3.0 & 7.3 & 4.0 & 14.6 & 4.2 & 13.2 & 3.8 & 12.4 & 2.2 & 4.9 & 18.6 \\
\hline Ethanol & 1.9 & 4.4 & 2.9 & 10.8 & 3.3 & 18.2 & 11.4 & 15.1 & 4.2 & 15.3 & 26.5 \\
\hline
\end{tabular}


Table 3

Major compounds in ethyl ether extractant analyzed by GC-MS

\begin{tabular}{|c|c|c|c|c|c|}
\hline \multirow[t]{2}{*}{ No. } & \multirow[t]{2}{*}{$\mathrm{RT}(\min )$} & \multicolumn{3}{|c|}{ Solvent (area\%) } & \multirow[t]{2}{*}{ Compound name } \\
\hline & & Water & Ethanol & Acetone & \\
\hline 1 & 4.16 & - & 4.13 & - & Acetic acid, hydroxy-, ethyl ester \\
\hline 2 & 4.79 & - & 4.54 & - & Propanoic acid, 2-hydroxy-ethyl ester \\
\hline 3 & 5.16 & - & - & 7.94 & 2-Methoxy-furan \\
\hline 4 & 5.16 & 1.44 & - & - & 2-Cyclopenten-1-one, \\
\hline 5 & 5.67 & - & - & 3.14 & $(+-)-4$-Amino-4,5-dihydro-2(3H)-furanone \\
\hline 6 & 6.82 & 1.76 & - & - & 2-Cyclopenten-1-one,2-methy- \\
\hline 7 & 6.83 & - & 3.12 & - & Butaoic acid, 2-hydroxy-, ethyl ester \\
\hline 8 & 5.95 & - & 3.20 & 2.71 & 3-Furanmethanol \\
\hline 9 & 7.82 & 1.96 & - & 3.54 & 2,5-Hexanedione \\
\hline 10 & 8.27 & 1.26 & - & - & 2-Cyclopenten-1-one, 3-methy- \\
\hline 11 & 8.71 & 1.99 & 1.37 & - & Phenol \\
\hline 12 & 9.14 & - & 1.11 & - & Pentanoic acid, 2-hydroxy-ethyl ester \\
\hline 13 & 9.82 & 1.09 & - & - & 2(3H)-Furanone, 5-ethyldihydro-3-methyl \\
\hline 14 & 9.88 & - & - & 2.78 & 3-Methyl-2,4-hexanedione \\
\hline 15 & 10.08 & - & 2.52 & 1.06 & 1,2-Cyclopentanedione, 3-methyl- \\
\hline 16 & 10.39 & - & - & 1.27 & 3(2H)-Furanone, 2-hexyl-5-methyl- \\
\hline 17 & 10.56 & - & 1.14 & - & 1,3-Dioxolane, 2-methyl-2-propyl- \\
\hline 18 & 10.74 & - & 1.70 & - & Pentanoic acid, 4-oxo-, ethyl ether \\
\hline 19 & 11.12 & 2.48 & - & - & Phenol, 4-methyl- \\
\hline 20 & 11.17 & - & - & 2.92 & Thiazole, 5-methyl- \\
\hline 21 & 11.18 & - & 3.80 & - & Butanoic acid, (tetrahydro-2-furanyl) methyl ester \\
\hline 22 & 11.52 & 17.20 & 4.39 & 2.70 & Phenol, 2-methoxy- \\
\hline 23 & 12.19 & - & - & 1.73 & Hexanethioic acid, S-propyl ester \\
\hline 24 & 12.61 & - & 2.80 & - & 1,4-Benzenediol, 2-methoxy- \\
\hline 25 & 13.62 & - & - & 1.50 & 1,2-Benzenediol, 3-methoxy- \\
\hline 26 & 13.69 & - & 2.20 & - & Butanedioic acid, diethyl ester \\
\hline 27 & 14.01 & - & - & 2.68 & Trans-furfurylideneacetone \\
\hline 28 & 14.13 & 7.69 & 8.23 & 2.98 & Phenol, 2-methoxy-4-methyl- \\
\hline 29 & 14.16 & 10.00 & 3.57 & 4.05 & 1,2-Benzenediol \\
\hline 30 & 15.07 & - & 1.93 & - & 1,3-Dioxepane, 5-methyl-2-pentadecyl \\
\hline 31 & 15.11 & - & - & 2.83 & Sulfurous acid, butyl-cyclohexyl-methyl ester \\
\hline 32 & 15.33 & - & - & 1.16 & Ethanone, 1-(2,5-dihydroxyphenyl)- \\
\hline 33 & 15.37 & - & 3.16 & - & 1,3-Dixepane, 5-methyl-2-pentadecyl- \\
\hline 34 & 15.73 & - & 2.75 & - & 2-Furanmethanol, tetrahydro \\
\hline 35 & 15.85 & 1.72 & 1.65 & - & 1,2-Benzenediol, 3-methyl- \\
\hline 36 & 15.95 & 3.94 & - & - & Hydroquinone \\
\hline 37 & 16.15 & - & 1.23 & - & 3-Buten-2-ol, 2-methyl- \\
\hline 38 & 16.35 & 3.07 & - & 9.49 & 1,2-Benzenediol, 4-methyl- \\
\hline 39 & 16.74 & - & 1.27 & - & Butanoic acid, 3,3-dimethyl-2-(1-methylethyl)-, methyl ester \\
\hline 40 & 17.54 & - & - & 1.62 & 4-Hydroxy-3-methylacetophenone \\
\hline 41 & 17.68 & 4.25 & - & - & 1,4-Benzenediol, 2-methyl- \\
\hline 42 & 18.00 & - & 1.94 & - & Phenol,2-methoxy-4-propyl- \\
\hline 43 & 18.01 & - & 1.12 & - & Eugenol \\
\hline 44 & 18.23 & 2.02 & - & - & 1,2,3-Benzentriol \\
\hline 45 & 18.25 & - & 2.98 & - & 4-Methoxycarbonyl-4-butanolide \\
\hline 46 & 18.71 & - & - & 1.59 & 1,4'-Bipiperidine \\
\hline 47 & 18.75 & 1.70 & 1.44 & - & Vanillin \\
\hline 48 & 18.89 & 1.00 & - & 3.43 & Ethanone, 1-(3-hydroxyphenyl)- \\
\hline 50 & 20.36 & - & 3.70 & 1.70 & Phenol, 2-methoxy-4-(1-propenyl)-, (E)- \\
\hline 49 & 20.43 & - & 3.48 & - & 2-Furancarboxylic acid, tetrahtdro-3-methyl-5-oxo- \\
\hline 51 & 20.59 & 1.64 & 1.19 & 8.00 & Ethanone, 1-(4-hydroxy-3-methoxyphenyl)- \\
\hline 52 & 20.65 & - & - & 1.09 & Ethanone, 1-(3-hydroxy-4- methoxyphenyl)- \\
\hline 53 & 21.52 & 3.80 & 2.72 & - & Homovanillyl alcohol \\
\hline 54 & 21.82 & - & - & 2.26 & Benzoic acid, 2,3-dihydroxy- \\
\hline 55 & 22.152 & - & - & 1.02 & Pyrrolidine, 1-(1-cyclopenten-1-yl)- \\
\hline 56 & 24.35 & 3.60 & - & - & 4-Amino-2-hydroxytoluene \\
\hline 57 & 24.72 & 5.80 & 4.77 & 2.75 & Benzeneacetic acid, 4-hydroxy- 3- methoxy- \\
\hline Tota & & 79.43 & 83.18 & 77.92 & \\
\hline
\end{tabular}

- Not detected or peak area less than $1 \%$ of total area.

The pinewood liquefaction oil was a quite complex mixture. It can be seen from Table 3 and Table 4 that: (1) the most constituted compounds were phenol derivatives hydrocarbon and (2) solvent type markedly affected the product distribution. In contrast to acetone and ethanol, solvent water liquefaction products had the shortest product distribution range with only 44 compounds (area $>1 \%$ ) identified in the oil product. When ethanol was employed as solvent, many products fall on the methyl- or ethyl-ester compounds. Some ester compounds' formation could be suggested according to the previous reports $[17,18,20,24,25]$. For instance, butanoic acid, (tetrahydro-2-furanyl)-methyl ester possibly pro- duced via esterification reaction between solvent ethanol derived butanoic acid and tetrahydro-2-furanmethanol. And some compounds, e.g., trans-furfurylidene acetone generated in the solvent acetone liquefaction process were through aldol condensation reaction between solvent acetone and biomass-derived 3-furanmethanol.

It was worthily noted that less compounds with nitrogen and sulfur atom were detected in the oils obtained in the present study compared with previous reports [14-16]. The lower heteroatom content may relate to the higher temperature $(623 \mathrm{~K})$. The higher temperature gave rise to thorough decomposition of heteroatom- 
Table 4

Major compounds in acetone extractant analyzed by GC-MS

\begin{tabular}{|c|c|c|c|c|c|}
\hline \multirow[t]{2}{*}{ No. } & \multirow[t]{2}{*}{ RT (min) } & \multicolumn{3}{|c|}{ Solvent (area\%) } & \multirow[t]{2}{*}{ Compound name } \\
\hline & & Acetone & Water & Ethanol & \\
\hline 1 & 4.48 & 5.48 & - & - & 2-Pentanone, 3-methylene \\
\hline 2 & 5.35 & 1.50 & 1.49 & 1.75 & 2-Pentanone, 4-hydroxy-4-methyl- \\
\hline 3 & 7.35 & 1.01 & - & - & 2,5-Hexanedione \\
\hline 4 & 8.24 & - & 1.01 & - & 2-Cyclopenten-1-one, 2-methyl- \\
\hline 5 & 11.02 & 1.27 & 1.18 & - & Phenol, 3-methyl- \\
\hline 6 & 11.17 & - & - & 1.32 & Butanoic acid, (tetrahydro-2-furanyl)methyl ester \\
\hline 7 & 11.44 & 1.57 & 9.83 & 2.14 & Phenol, 2-methoxy- \\
\hline 8 & 13.40 & 1.20 & - & - & 2-Butanone, 4-(5-methyl-2-furanyl) \\
\hline 9 & 23.67 & - & - & 1.41 & Butanedioic acid, diethyl ester \\
\hline 10 & 13.84 & 1.93 & - & - & Trans, furfurylidene acetone \\
\hline 11 & 14.00 & 2.15 & 5.30 & 3.06 & Phenol, 2-methoxy-4-methyl- \\
\hline 12 & 14.11 & 1.42 & - & - & Trans-2-(1-hydroxycyclohexyl)-furan \\
\hline 13 & 15.36 & - & - & 1.22 & 4-Methylurazole \\
\hline 14 & 15.98 & 3.79 & 4.27 & 5.78 & Phenol, 4-ethyl-2-methoxy- \\
\hline 15 & 16.04 & 2.84 & - & - & Benzene, 1,4-dimethoxy-2-methyl- \\
\hline 16 & 16.64 & 2.03 & - & - & Ethanone, 1-(2-hydroxy-5-methylphenyl)- \\
\hline 17 & 17.79 & 1.04 & - & 2.31 & Eugenol \\
\hline 18 & 18.01 & 2.48 & - & 5.37 & Phenol, 2-methoxy-4-propyl- \\
\hline 19 & 18.65 & 1.00 & 1.06 & - & Ethanone, 1-(3-hydroxyphenyl)- \\
\hline 20 & 18.69 & - & 1.38 & - & Vanillin \\
\hline 21 & 18.89 & 1.32 & - & - & 1,4-Benzenediol, 2,6-dimethyl- \\
\hline 22 & 19.80 & 4.54 & - & 11.85 & Phenol, 2-methoxy-4-(1-propenyl)-(E) \\
\hline 23 & 20.53 & 1.25 & - & - & Ethanone, 1-(4-hydroxy-3-methoxyphenyl)- \\
\hline 24 & 21.43 & - & 1.06 & 1.06 & 6-Amino-2,4-dimethylphenol \\
\hline 25 & 21.45 & - & 4.11 & 1.59 & Benzene acid, 4-hydroxy-3-methoxy- \\
\hline 26 & 22.53 & - & - & 1.21 & Benzoic acid, 4-hydroxy-3-methoxy-ethyl ester \\
\hline 27 & 23.77 & - & 1.32 & 4.15 & Benzene, $1,1^{\prime}$-(1,3-propanediyl)bis- \\
\hline 28 & 23.78 & 1.12 & - & - & Homovanillyl alcohol \\
\hline 29 & 24.35 & - & - & 1.78 & Benzene, 1,1'-(1-methyl-1,3-propanediyl)bis- \\
\hline 30 & 28.77 & - & 1.36 & - & 2,4-Dihydroxyphenyl-2-phenyl ethyl ester \\
\hline 31 & 30.74 & - & - & 1.52 & 2,3-Dimethyl-1,4,4a,9a-tetrahydroanthracene-9,10-dione \\
\hline 32 & 31.79 & - & 1.34 & - & 2-(1-Hydroxyisoamyl)-1-methoxy benzene \\
\hline 33 & 31.85 & 1.28 & - & - & 10,18-Bisnorabieta-5,7,9(10),11,13-pentaene \\
\hline 34 & 31.86 & - & - & 2.12 & $3^{\prime}, 4^{\prime}$-Diisopropylbiphenyl \\
\hline 35 & 31.89 & - & 1.66 & - & 9-Octadecenoic acid, $(E)$ - \\
\hline 36 & 32.16 & - & - & 1.84 & Linoleic acid ethyl ester \\
\hline 37 & 32.25 & - & - & 3.24 & Ethyl oleate \\
\hline 38 & 32.61 & - & - & 1.36 & 1-[4-(2-p-Tolyvinyl)phenyl] ethanone \\
\hline 39 & 33.08 & - & 1.81 & 1.26 & Phenanthrene,1-methyl-7-(1-methylethyl)- \\
\hline 40 & 33.29 & - & 1.16 & - & 4,4'-Thiobis(2-methylethyl)- \\
\hline 41 & 34.24 & - & - & 5.61 & 4-Methoxy-2-hydroxy stibene \\
\hline 42 & 34.30 & 4.29 & - & - & 9H-xanthen-9-one,2-methoxy- \\
\hline 43 & 34.50 & - & 1.51 & - & Butanoic acid,4-[1-(oxobutyl)amino]phenyl ester \\
\hline 44 & 34.51 & 1.08 & - & 1.49 & Phenol, 3-amino \\
\hline 45 & 34.67 & - & 7.95 & 2.39 & Benzenacetic acid, 4-hydroxy-3-methoxy-, methyl ester \\
\hline 46 & 34.68 & 2.16 & - & - & Propan-2-one, 1-(4-isoproxy-3-methoxyphenyl- \\
\hline 47 & 34.79 & 1.43 & - & - & 4,4'-Diacetyldiphenylmethane \\
\hline 48 & 34.86 & - & 1.42 & - & Benzaldehyde acid, 3-[4(1,1-dimethylethyl)phenoxy]- \\
\hline 49 & 34.88 & 1.88 & - & 6.63 & Phthalic acid, di(3-methylphenyl)ester \\
\hline 50 & 35.35 & - & - & 2.26 & Methanone, (3,4-dimethylphenyl)(2,4,6-trimethylphenyl)- \\
\hline 51 & 36.06 & - & - & 1.64 & Phenol, 4,4'-methylenebis[2,6-dimethyl]- \\
\hline 52 & 36.35 & 9.25 & 16.63 & 9.38 & 1-Phenanthrenecarboxylic acid, 1,2,3, 4,4a,9,10,10a-octahydro-1,4a-Dimethyl-7-(1-methyl)-, methyl ester,(1R,4aS,10aR)- \\
\hline 53 & 37.98 & - & - & 1.44 & 4,4'-Dimethoxy-biphenyl-2-carboxylic acid,methyl ester \\
\hline 54 & 38.81 & - & 1.18 & 2.70 & 10,11-Dihydro-10-hydroxy-2,3-dimethoxydibenz(b,f)oxepin \\
\hline 55 & 38.84 & 2.53 & - & - & 6H-Dibenzo[b,d]pyran-6-one,3,7dihydro-9-methoxy-1-methyl- \\
\hline 56 & 42.10 & - & - & 2.61 & 4-Methoxy-benzenmethanol \\
\hline 57 & 42.16 & 2.37 & - & - & Benzeneacetic acid, 4-hydroxy-3- methoxy-,methyl ester \\
\hline 58 & 42.17 & - & 5.92 & - & Benzeneethanamine, 3-hydroxy-4-methoxy- \\
\hline 59 & 44.38 & - & 2.01 & - & 2H-1-benzopyran-2-one,4,5,7-trimethoxy-3-(4-methoxyphenyl)- \\
\hline \multicolumn{2}{|c|}{ Total area } & 65.21 & 75.96 & 93.48 & \\
\hline
\end{tabular}

- Not detected or peak area less than $1 \%$ of total area.

containing polymer (e.g., protein) and the elimination of heteroatoms like nitrogen, sulfur and so on.

\subsection{FTIR analysis of the solid residue}

The FTIR spectra of the raw pinewood and the solid residues after liquefaction with three tested solvents were shown in Fig. 4. According to the literature [26], the bands in the spectra of raw pinewood were assigned as follows. The bands at $3390 \mathrm{~cm}^{-1}$ was caused by $-\mathrm{OH}$ in pinewood and water. Absorption at $2920 \mathrm{~cm}^{-1}$ was attributed to the symmetric $\mathrm{CH}_{3}$-vibration of methoxy group and the band at $1060 \mathrm{~cm}^{-1}$ represented the $\mathrm{C}-\mathrm{O}$ stretch vibration for the $\mathrm{O}-\mathrm{CH}_{2}$. The band at $1600 \mathrm{~cm}^{-1}$ and bands from $1400 \mathrm{~cm}^{-1}$ to $1640 \mathrm{~cm}^{-1}$ belonged to the aryl group ( $1600 \mathrm{~cm}^{-1}$ for the benzene backbone vibration). The presence of the $C=O$ was suggested by the absorption at $1640 \mathrm{~cm}^{-1}$. The reason for the broad band at $3390 \mathrm{~cm}^{-1}$ was contributed to the combination and overlap of absorption of aliphatic and aromatic $\mathrm{O}-\mathrm{H}$, 


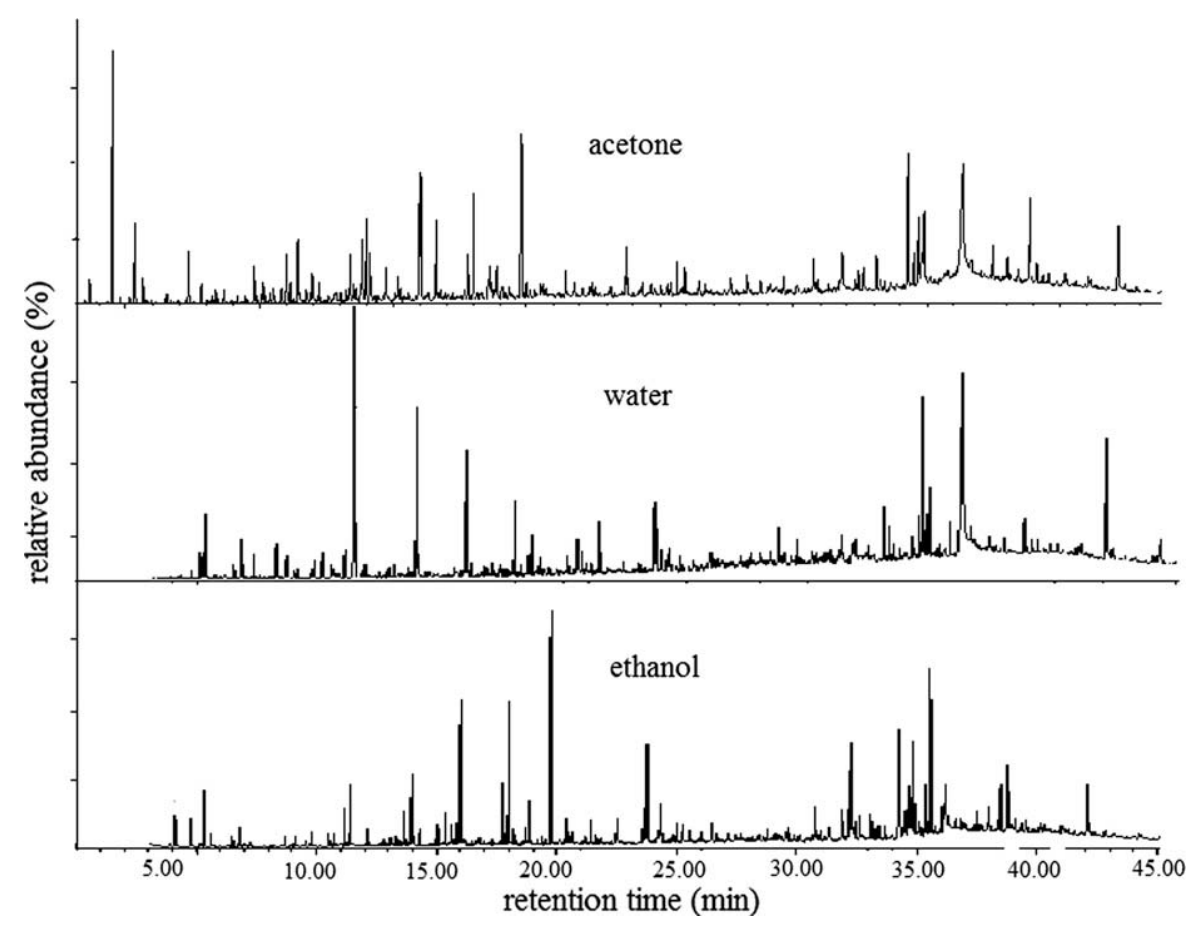

Fig. 3. GC-MS spectra of oil B from the tested solvents. Conditions: temperature $623 \mathrm{~K}$, reaction time 20 min, starting pressure $1 \mathrm{MPa}$.

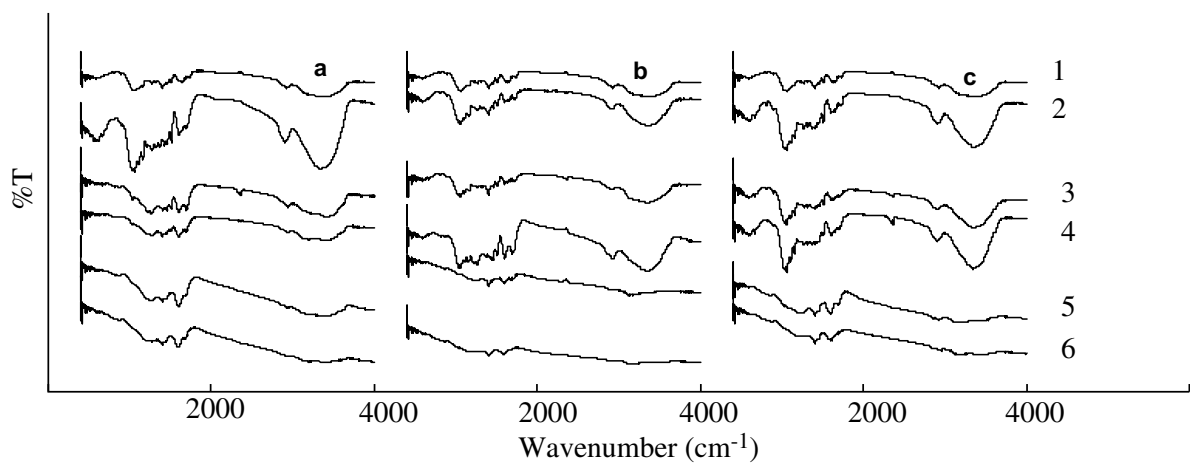

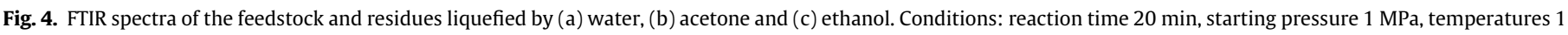
- feedstock, $2-523 \mathrm{~K}, 3-573 \mathrm{~K}, 4-623 \mathrm{~K}, 5-673 \mathrm{~K}$ and $6-723 \mathrm{~K}$.

$\mathrm{Ar}-\mathrm{H},=\mathrm{C}-\mathrm{H}$ and $\mathrm{N}-\mathrm{H}$ stretching. The peaks between $1000 \mathrm{~cm}^{-1}$ and $600 \mathrm{~cm}^{-1}$ were from the out-of-plane vibrations of methyl or other alkyl constituents on the aromatic group. The pinewood is mainly constituted of cellulose, hemicellulose and lignin. From the analysis of the band above, it can be concluded that the band at $1640 \mathrm{~cm}^{-1}(\mathrm{C}=0)$ represents the hemicellulose. The absorption at $1060 \mathrm{~cm}^{-1}$ represents the cellulose ( $\beta$ glycosidic bond) and absorption at $1400 \mathrm{~cm}^{-1}$ and $1600 \mathrm{~cm}^{-1}$ (benzene ring) represents the lignin.

The band at $1640 \mathrm{~cm}^{-1}$ almost disappeared after $523 \mathrm{~K}$ liquefaction showing that hemicellulose's decomposition preceded lignin and cellulose in all tested solvents. Solvent's effect on pinewood liquefaction can be clearly seen from the cellulose decomposition. As seen from Fig. 4, water compared with acetone and ethanol gave priority to cellulose decomposition at lower temperature (about $573 \mathrm{~K}$ ) and this can be confirmed by the substantial decrease of absorption intensities of cellulose. Relative higher content of cellulose can be confirmed by high intensity of band at $1060 \mathrm{~cm}^{-1}$ when ethanol and acetone as solvent after $623 \mathrm{~K}$ liquefaction. The disappearance of bands at $1640 \mathrm{~cm}^{-1}$ and $1060 \mathrm{~cm}^{-1}$ showed the cellu- lose and hemicellulose was almost totally transformed after $673 \mathrm{~K}$ liquefaction except in ethanol solvent. The only weak absorption at $1400 \mathrm{~cm}^{-1}$ and $1600 \mathrm{~cm}^{-1}$ bands implied the existence of lignin fragments in the solid residue besides solid carbon. It can be seen that the decomposition velocity of cellulose, hemicellulose and lignin was different in tested solvents resulting in different product category and relative abundance.

\section{Conclusions}

Liquefaction of biomass with proper solvents is a process that can promisefully be integrated with optimized conditions to simultaneously produce fuel additives and valuable chemicals. In the present study, the highest conversion rate was obtained when acetone was employed as liquefaction solvent and the maximum oil yield was found to be $26.5 \%$ in ethanol liquefaction process. The product distribution was also strongly affected by the solvent type. The major hydrocarbons were 2-methoxy-phenol, 1-PA acid and 4-hydroxy-3-methoxy-benzeneacetic acid in the case of water liquefaction process. The composition of oil from acetone 
liquefaction process consisted mainly of 1-PA acid, 2-methoxy-furan, 4-methyl-1,2-benzenediol-1-(4-hydroxy-3-methoxy-phenyl)ethanone. While solvent ethanol was favorable for the formation of (E)-2-methoxy-4-(1-propenyl)-phenol and 2-methoxy-4methyl-phenol. The solid residue mainly consisted of solid carbon with little amount of lignin fragments at $723 \mathrm{~K}$. The study has shown that employing different solvents could change the distribution and relative abundance of produced compounds. Further research is needed to select effective solvent with proper catalyst to narrow the product distribution and produce desired compounds to make the process more industrial.

\section{Acknowledgements}

This research was financially supported by the National Key Technology R\&D Program (2008BAC32B03) and the National Basic Research Program (2007CB407303) of China.

\section{References}

[1] Hoffert MI, Caldeira K, Benford G, Criswell DR, Green C, Herzog H, et al. Advanced technology paths to global climate stability: energy for a greenhouse planet. Science 2002;298:981-7.

[2] Pacala S, Socolow R. Stabilization wedges: solving the climate problem for the next 50 years with current technologies. Science 2004;305:968-72.

[3] Demirbas A. Biomass resource facilities and biomass conversion processing for fuels and chemicals. Energy Convers Manage 2001;42(11):1357-78.

[4] Meier D, Faix O. State of the art of applied fast pyrolysis of lignocellulosic materials -a review. Bioresour Technol 1999;68(1):71-7.

[5] Chandrakant P, Bisaria VS. Simultaneous bioconversion of cellulose and hemicellulose to ethanol. Crit Rev Biotechnol 1998;18(4):295-331.

[6] Ye S, Cheng J. Hydrolysis of lignocellulosic materials for ethanol production: a review. Bioresour Technol 2002;83(1):1-11.

[7] Bridgwater AV, Maniatis K. The production of biofuels by the thermochemical processing of biomass, in molecular to global photosynthesis. In: Archer Md, Barber J, editors. London UK: IC Press; 2004. p. 521-612.

[8] Yaman S. Pyrolysis of biomass to produce fuels and chemical feedstocks. Energy Convers Manage 2004;45(5):651-71.
[9] Nordon P, Young BC, Bainbridge NW. The rate of oxidation of char and coal in relation to their tendency to self-heat. Fuel 1979;58(6):443-9.

[10] Makabe M, Ouchi K. Effect of pressure and temperature on the reaction of coal with alcohol-alkali. Fuel 1981;60(4):327-9.

[11] Demirbas A. Mechanisms of liquefaction and pyrolysis reactions of biomass. Energy Convers Manage 2000;41(6):633-46.

[12] Yan Y, Xu J, Li T, Ren Z. Liquefaction of sawdust for liquid fuel. Fuel Process Technol 1999;60(2):135-43.

[13] Karagoz S, Bhaskar T, Muto A, Sakata Y. Effect of Rb and Cs carbonates for production of phenols from liquefaction of wood biomass. Fuel 2004;83(1718):2293-9.

[14] Karagoz S, Bhaskar T, Muto A, Sakata Y, Oshiki T, Kishimoto T. Lowtemperature catalytic hydrothermal treatment of wood biomass: analysis of liquid products. Chem Eng J 2005;108(1-2):127-37.

[15] Karagoz S, Bhaskar T, Muto A, Sakata Y, Uddin MA. Low-temperature hydrothermal treatment of biomass: effect of reaction parameters on products and boiling point distributions. Energy Fuels 2004;18(1):234-41.

[16] Karagoz S, Bhaskar T, Muto A, Sakata Y. Catalytic hydrothermal treatment of pine wood biomass: effect of $\mathrm{RbOH}$ and $\mathrm{CsOH}$ on product distribution. J Chem Technol Biotechnol 2005;80:1097-102.

[17] Jakab E, Liu K, Meuzelaar HLC. Thermal decomposition of wood and cellulose in the presence of solvent vapors. Ind Eng Chem Res 1997;36(6):2087-95.

[18] Demirbas A. A new method on wood liquefaction. Chim Acta Turc 1985;13: 363-8.

[19] Cemek M, Kucuk MM. Liquid products from verbascum stalk by supercritical fluid extraction. Energy Convers Manage 2001;42(2):125-30.

[20] Miller JE, Evans L, Littlewolf A, Trudell DE. Batch microreactor studies of lignin and lignin model compound depolymerization by bases in alcohol solvents. Fuel 1999;78(11):1363-6.

[21] Yamada T, Ono H. Rapid liquefaction of lignocellulosic waste by using ethylene carbonate. Bioresour Technol 1999;70(1):61-7.

[22] Kabyemela BM, Adschiri T, Malaluan RM, Arai K, Ohzeki H. Rapid and selective conversion of glucose to erythrose in supercritical water. Ind Eng Chem Res 1997;36(12):5063-7.

[23] Antal MJ, Leesomboon T, Mok WS, Richards GN. Mechanism of formation of 2furaldehyde from xylose. Carbohydr Res 1991;217:71-85.

[24] Wang D, Montane D, Chornet E. Catalytic steam reforming of biomass-derived oxygenates: acetic acid and hydroxyacetaldehyde. J Appl Catal A: Genera 1996;143(2):245-70.

[25] Klein MT. Lignin thermolysis pathway, Doctor's thesis. Massachussetts institute of technology; 1981.

[26] Lizbeth laureano-perez. Spectroscopic and chemical characterization of biomass, Doctor's thesis. Michigan State University; 2005. 